\title{
Squaring circle of US energy
}

The much-awaited US energy strategy, sensible enough in many ways, is a disappointment on the central issue of how oil consumption should be constrained.

How would the world, and the United States in particular, be changed if the cost of a new motor-car were $\$ 100$ and the price of petrol (gasoline) were double what it is at present, say $\$ 4$ rather than $\$ 2$ a gallon? Car-owners would not be impoverished, for the numbers roughly load the cost of owning a medium-sized car onto the cost of buying the petrol required to travel 100,000 miles. But market forces would see to it that car-ownership would increase and that travel (and petrol consumption) would sharply decrease. Of course, there is no obvious way of arranging that new cars should cost $\$ 100$ each, which would in any case be thoroughly uneconomic; people would buy Cadillacs and park them permanently in the street. But the benefits of reduced petrol consumption could be won more conventionally by increasing the tax. on petrol by $\$ 2$ a gallon and compensating car-users by reducing other taxes.

Such musings will no doubt have crossed the mind of Admiral James Watkins, the able US Secretary of Energy, during his year-long labours on the new Energy Strategy the White House released last week. The document starts from the principle that US dependence on imported oil must be decreased. It makes sensible, if controversial, proposals for increasing the indigenous supply of energy by exploiting environmentally sensitive oil reserves and by removing some impediments to the construction of nuclear plants. But the administration seems to have set its face against increased taxes on petrol, hoping instead to rely on still tougher regulations to improve the efficiency of new cars (and encourage the disposal of older inefficient cars). The trouble is that the policy will not work or, more accurately, will do so only at needless economic cost - that of retiring old cars prematurely, for example.

\section{Endowment}

The United States, although better endowed than most other countries with natural resources, is peculiarly placed on energy: a greater proportion of US energy consumption is based on liquid and gaseous hydrocarbons than in other countries except those of the Middle East. The explanation is mostly historical, and owes much to the ingenuity with which various forms of the internal combustion engine have been adapted to the conquest of distance. The question with which Watkins has been wrestling is whether the time has come for NATURE · VOL $349 \cdot 28$ FEBRUARY 1991 an historically perceptible change of direction.

\section{Tradition}

Traditionally, the US government has also always been active in moulding the framework of the petroleum business. In the 1920s, the Texas Railroad Commission was a way of subsidizing then-distant oil producers (who also enjoyed substantial tax incentives). More recently, the Inter-State Commerce Commission has shielded naturalgas consumers in the northeast from market prices by regulating the prices gas-pipeline operators charge. Past energy strategy, in other words, has not been to balance supply and demand by the price mechanism, but to help producers with tax incentives and, when seemly, to shield consumers from prices that reflect true costs. These devices stimulated both consumption and fears that supply would be exhausted, whence the designation of important oilfields as strategic reserves and the ban on exports of crude petroleum.

Times have now changed, but the policy has not. Although both Germany and Japan depend entirely on imported oil, that will not do for the United States, which fears the economic disruption caused by fluctuations of the price of oil as well as the secular upward trend of world prices there will be as the more accessible oilfields are worked out. Whence Watkins and his strategy. But the administration has evidently been constrained by its memories of last year's bruising budget compromise, which eventually included a modest federal tax on petrol.

Yet oil consumption would be most simply and surely reduced by increasing its price, either by an import tariff (opposed by the oil companies) or an excise tax (hated by consumers, many of whom are also voters). Specifying improved efficiency by regulation is by contrast an uncertain course: people do not always keep their cars in prime condition (which is in any case expensive), the cost of new cars would be driven up (which would be irremedially deflationary) while there are physical as well as practical limits to the improvement of efficiency. (Has the Department of Energy heard of Carnot's theorem?) On the complaint that higher gasoline taxes would hurt the poor, there are two things to say: first, if the cost of food and other necessities is a component in the calculation of welfare, why not have gasoline stamps as well as food stamps? and, second, why not soak the gas-guzzlers in the cause of social equity? 